\title{
Stem cell therapy for stroke: lessons learned from recent successful randomized trials of interventional therapy for stroke
}

\author{
Oh Young Bang ${ }^{1,2}$
}

${ }^{1}$ Department of Neurology, Samsung Medical Center, Sungkyunkwan University School of Medicine, Seoul, Korea

${ }^{2}$ Translational and Stem Cell Research Laboratory on Stroke, Samsung Medical Center, Seoul, Korea

Received: May 8, 2018

Revised: May 9, 2018

Accepted: May 18, 2018

Corresponding author:

Oh Young Bang

Department of Neurology,

Samsung Medical Center,

Sungkyunkwan University

School of Medicine, 81 Irwon-

ro, Gangnam-gu, Seoul 06351 , Korea

Tel: +82-2-3410-3599

E-mail:

ohyoung.bang@samsung.com

\begin{abstract}
Cell-based therapy is a promising approach for treating acute stroke patients as well as those with fixed neurological deficits, and therefore, the number of stem cell trials conducted on stroke patients is increasing. However, more studies are needed to conclude the efficacy of stem cell therapy because while several studies showed a beneficial effect, there was significant bias in subsequent studies. Meanwhile, there have been recent advances in stroke treatment such as endovascular therapy for acute ischemic stroke and catheter-based closing of a patent foramen ovale in cryptogenic stroke. Clinical trials of the latter two interventional therapies have very similar histories of consistent success after repeated failures. In this review, the factors related to the success of these interventional therapies are discussed and applied to stem cell therapy for stroke patients. Through continued efforts, there is hope for success in stem cell therapy for stroke patients.
\end{abstract}

Keywords: Clinical trial; Endovascular therapy; Foramen ovale, patent; Stem cells; Stroke
This is an Open Access article distributed under the terms of the Creative Commons Attribution Non-Commercial License (http:// creativecommons.org/licenses/ by-nc/4.0/).

\section{INTRODUCTION}

The lifetime risk of stroke is one in six worldwide. Although there have been recent advances in stroke therapy, including antithrombotic agents for stroke prevention and endovascular therapy for acute ischemic stroke, stroke is still one of the leading causes of death and physical disability in adults. Cell-based therapy could be a promising approach for treating acute stroke patients as well as those with fixed neurological deficits.

This review presents the future outlook of cell-based therapy, focusing on the clinical viewpoint. Recently, there have been advances in the field of interventional therapy for stroke, i.e., endovascular therapy for acute ischemic stroke and catheter-based closing of a patent foramen ovale (PFO) in cryptogenic stroke. Clinical trials of these two interventional therapies have very similar histories of consistent success after repeated failure. In this review, the factors related to the success of these interventional therapies for stroke patients are discussed and ap- 
plied to stem cell therapy for stroke patients.

\section{CURRENT STATUS OF STEM CELL THERAPY FOR STROKE}

With the increase in the number of publications on stem cell therapy for experimental stroke and our understanding of the mechanisms of stem cells in recovery after stroke, the number of clinical trials on stem cell therapy in stroke patients is increasing [1]. However, a systemic review and meta-analysis of preclinical studies of stem cell therapy for stroke showed that the study quality was low in terms of randomization, blinded outcome assessment, and sample size calculation, and that non-randomized studies gave significantly higher estimates of improvement in structural outcome, suggesting publication bias [2]. Similarly, a review of clinical trials of stem cell therapy for stroke patients showed that while stem cells appeared to be of some benefit in several studies there was significant bias in subsequent studies [1]. Only a few randomized controlled trials have been conducted, i.e., intravenous application of autologous bone marrow mononuclear cells [3], mesenchymal stem cells (MSCs) [4], and bone marrow-derived allogeneic stem cells [5]. Therefore, more studies are needed to conclude the efficacy of stem cells.

However, stroke patients often have high expectations that stem cell therapy will improve their function [6]. Although there is insufficient clinical evidence to support its efficacy, stem cell therapy is being performed worldwide. Dina Fine Maron reported on Scientific American (June 30, 2016) that more than 550 clinics around the United States offer unproven stem cell therapies for various diseases and injuries. Many expert groups emphasized the responsibility of heath care professionals to counsel and educate patients regarding the risk-benefits of this possible harmful experimental treatment. Experts are also concerned about 'stem cell tourism,' an internet-based industry in which stem cell procedures are advertised to patients as a 'cure' [7-9]. We have learned from experimental hematology that a 60-year time span was required to develop the first successful stem cell therapy, the transplantation of hematopoietic stem cells [10]. Prockop et al. [10] stated that history indicates that the development of a dramatically new therapy usually requires patience and a constant dialogue between basic scientists and physicians carrying out carefully designed clinical trials.

\section{LESSENS FROM OTHER STROKE THERAPIES}

Recent advances in stroke treatment include endovascular therapy and PFO closure. Clinical trials of these two have very similar histories of consistent success after repeated failure.

\section{Endovascular therapy}

Acute treatments for ischemic stroke include intravenous tissue plasminogen activator and endovascular treatment (EVT). EVT has been promising but remained unproven after negative trials on the treatment were published in 2013 [1113]. The Interventional Management of Stroke III (IMS-III) [11], Mechanical Retrieval and Recanalization of Stroke Clots Using Embolectomy (MR RESCUE) [12], and Intra-Arterial Versus Systemic Thrombolysis for Acute Ischemic Stroke Expansion (SYNTHESIS EXP) [13] trials were multicenter, prospective randomized controlled trials (RCTs) which failed to show a benefit from EVT for acute ischemic stroke. Potential reasons for lack of benefit include wrong candidates (patients with a large infarct core or no large vessel occlusion), delays in time to angiographic reperfusion (especially in-hospital delay), and the use of older revascularization devices (these showed lower recanalization rates than stentriever). Combined with the lessons learned from the aforementioned three RCTs published in 2013, the Acute Stroke Imaging Research roadmap II provides guidance on the use of imaging in the design of stroke clinical trials to shorten the speed of revascularization and to avoid the futility of therapeutic intervention [14]. The most recent phase III RCTs have been conducted in 2015, Multicenter Randomized Clinical Trial of Endovascular Treatment for Acute Ischemic Stroke in the Netherlands (MR CLEAN) [15], Endovascular Treatment for Small Core and Anterior Circulation Proximal Occlusion With Emphasis on Minimizing CT to Recanalization Times (ESCAPE) [16], Extending the Time for Thrombolysis in Emergency Neurological Deficits- Intra-Arterial (EXTEND-IA) [17], and Solitaire With the Intention for Thrombectomy as Primary Endovascular Treatment for Acute Ischemic Stroke (SWIFT PRIME) [18] trials. Most of these studies addressed small core and large vessel occlusion, shortening the time before angiographic reperfusion and the use of stentriever devices. New evidence from these RCTs has demonstrated an overwhelming benefit of EVT for treatment of acute ischemic stroke secondary to large arterial occlusion. With the results of these trials, endovascular therapy using stentriever was approved worldwide for patients with acute ischemic stroke. 


\section{Patent foramen ovale closure}

Cryptogenic ischemic strokes comprise approximately 25\% of all ischemic stroke cases. The foramen ovale is a hole that exists in the wall between the left and right atria of every human fetus which normally closes during infancy. However, the foramen ovale does not close in approximately $25 \%$ of the general population. In certain patients, cryptogenic stroke is attributable to PFO $[19,20]$. Paradoxical embolism was considered a possible diagnosis if there was an arterial embolism without demonstrable sources; coexistence of deep venous thrombosis, pulmonary embolism, or existent of large right-left shunt via PFO. Three prospective RCTs tested whether endovascular PFO closure is superior to medical treatment in prevention of stroke or transient ischemic attack (TIA) in patients with cryptogenic stroke, but showed negative results in 2013; Randomized Clinical Trial Comparing Percutaneous Closure of Patent Foramen Ovale Using the Amplatzer PFO Occluder with Medical Treatment in Patients with Cryptogenic Embolism (PC) trial [21], Randomized Evaluation of Recurrent Stroke Comparing PFO Closure to Established Current Standard of Care Treatment (RESPECT) trial [22], and Evaluation of the STARFlex Septal Closure System in patients with a stroke or TIA (CLOSURE) trial [23]. Most stroke guidelines recommend limited use of PFO closure in certain situations $[24,25]$. Possible explanations for these failures have been discussed, e.g., wrong patients (inclusion of patients with TIA alone or small right-left shunt amount), wrong device (insufficient procedure success rate and risk of arrhythmia of the STARFflex device), and wrong outcome measures (short-term follow-up with low recur rate) [26]. The most recent phase III RCTs were conducted in 2017, RESPECT [27], Closure of Patent Foramen Ovale or Anticoagulants versus Antiplatelet Therapy to Prevent Stroke Recurrence (CLOSE) [28], Gore REDUCE [29], and device closure versus medical therapy for cryptogenic stroke patients with high-risk patent foramen ovale (DEFENSE-PFO) [30]. All four studies showed a significantly lower rate of stroke in patients who received PFO closure. Following the results of these trials, PFO closure therapy was approved by the Food \& Drug Administration for treatment of patients with cryptogenic ischemic stroke.

\section{Factors associated with success of RCTs}

The investigators of endovascular therapy and PFO closure trials were able to obtain success because they carefully analyzed the possible cause of previous failures. Interestingly, factors associated with the success of recent RCTs were similar between endovascular therapy and PFO closure trials
(Fig. 1). These factors may also be important in clinical trials of stem cell therapy, and are listed below [31].

\section{Selection of candidate patients}

Possible patient factors that may affect their response to stem cell therapy include gender and age of donor/recipient [32], comorbidity (such as diabetes) [33-35], and stroke medication (such as aspirin and statins) [36] which may affect endogenous and transplanted stem cells. Severity of brain injury may also be important since patients with extensive damage to the periventricular region were observed to have a lesser degree of improvement after stem cell therapy [4].

Recently, efforts have been made to select responders to stem cell therapy using blood biomarkers. Candidates for stem cell therapy biomarker included circulating chemokines [4], inflammatory cytokines [37], and microRNAs [38]. These biomarkers were found to be related to stem cell action and disease activity. Stroke patients often show spontaneous recovery. Efforts to preclude patients who may recover without intervention are therefore mandatory in clinical trials of stem cell therapy. A combination of clinical, electrophysiology and imaging features, such as Predicting Recovery Potential for the hand and arm (PREP) score, may be helpful for this purpose (Fig. 1, https://prepforstrokerehab.wikispaces.com) [39].

\section{Objective measurement of functional outcome}

In clinical trials of stroke patients, the modified Rankin Score (mRS), Barthel index, and National Institutes of Health Stroke Scale (NIHSS) are the most widely used functional outcome scales. The mRS measures the degree of disability or dependence in daily activities, whereas the Barthel index measures performance in 10 basic activities of daily living and mobility. Both require an interview with the patient or caregivers, and can be completed in 5 and 10 minutes, respectively. Each clinical score system has its own limitations, and are greatly influenced by many factors. In stroke trials, the impact of such covariates on outcome may be much larger than the treatment effect that is being measured [40,41]. More importantly, any functional gain after stroke can be obtained by 'functional compensation' rather than 'true recovery.'

Recently, imaging biomarkers are increasingly used in stroke trials employing the techniques of diffusion-tensor imaging (DTI) and resting state function magnetic resonance imaging (fMRI). DTI-based measurement of brain injury at baseline accounted for $38 \%$ of the variance in clinical gains [42]. Treatment-related gains in a clinical setting can be improved 


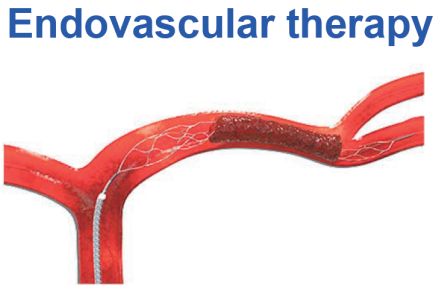

Failures in 2013

IMS III trial

SYSTHESIS Expansion

MR RESCUE

\section{Patient selection \\ 2. Device improvement}

3. Faster treatment
PFO closure

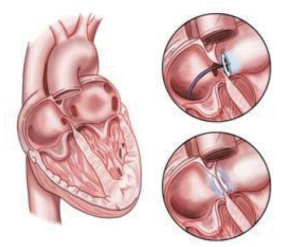

Failures in 2013

$\mathrm{PC}$ trial

RESPECT

CLOSURE I

\section{Stem cell therapy}

Optimal candidates

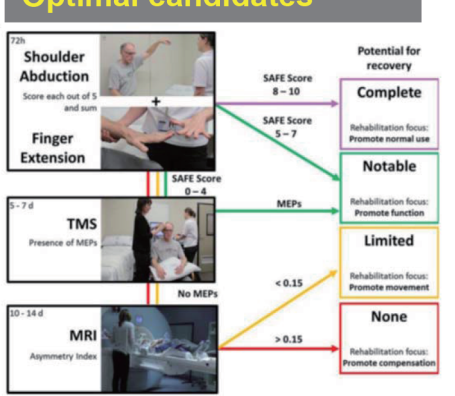

Success in 2015
MR CLEAN
ESCAPE
SWIFT PRIME

EXPAND-IA

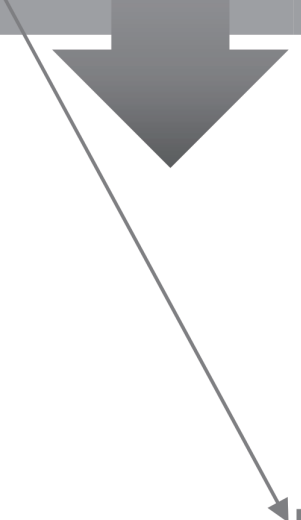

Faster application

Targeting neuroprotection and inflammation

BBB opening and increased chemoattractants at acute phase

CLOSE RESPECT

Gore REDUCE

DEFENSE-PFO
Success in 2017

Better cell products
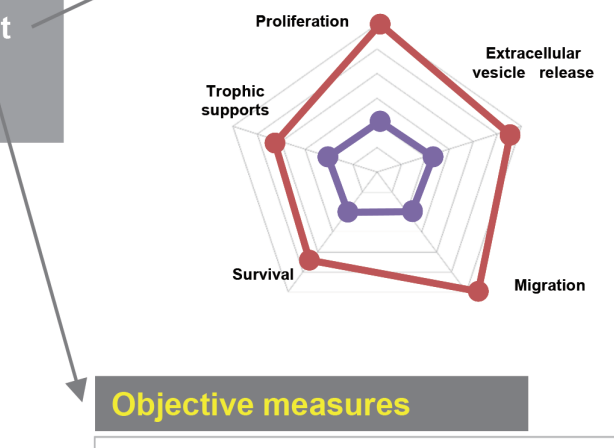

Objective measures

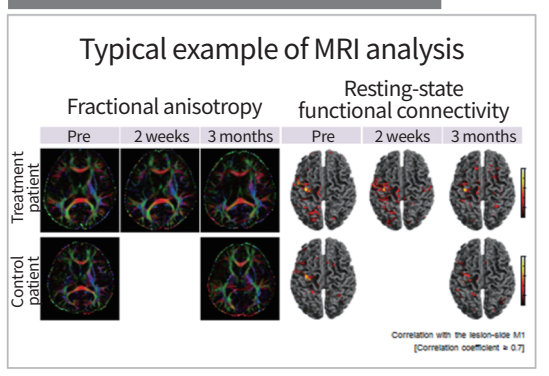

Fig. 1. Lessons from major clinical trials of endovascular therapy and patent foramen ovale (PFO) closure. IMS III, the Interventional Management of Stroke III; SYNTHESIS, Intra-Arterial Versus Systemic Thrombolysis for Acute Ischemic Stroke; MR RESCUE, Mechanical Retrieval and Recanalization of Stroke Clots Using Embolectomy; MR CLEAN, Multicenter Randomized Clinical Trial of Endovascular Treatment for Acute Ischemic Stroke in the Netherlands; ESCAPE, Endovascular Treatment for Small Core and Anterior Circulation Proximal Occlusion With Emphasis on Minimizing CT to Recanalization Times; SWIFT PRIME, Solitaire With the Intention for Thrombectomy as Primary Endovascular Treatment for Acute Ischemic Stroke; EXTEND-IA, Extending the Time for Thrombolysis in Emergency Neurological Deficits-Intra-Arterial; PC, Randomized Clinical Trial Comparing Percutaneous Closure of Patent Foramen Ovale Using the Amplatzer PFO Occluder with Medical Treatment in Patients with Cryptogenic Embolism; RESPECT, Randomized Evaluation of Recurrent Stroke Comparing PFO Closure to Established Current Standard of Care Treatment; CLOSURE I, Evaluation of the STARFlex Septal Closure System in patients with a stroke or TIA; CLOSE, Closure of Patent Foramen Ovale or Anticoagulants versus Antiplatelet Therapy to Prevent Stroke Recurrence; DEFENSE-PFO, device closure versus medical therapy for cryptogenic stroke patients with high-risk patent foramen ovale; BBB, blood-brain barrier; MEP, motor evoked potentials; TMS, transcranial magnetic stimulation; MRI, magnetic resonance imaging.

by fMRI-based measure of brain function [43]. In clinical trials of stem cell therapy, these imaging biomarkers (named recovery magnetic resonance imaging modalities) are increasingly being used [44-47].

\section{Faster application of stem cells}

It was generally accepted that stem cell therapy was the last resort for patients with fixed neurological deficits. However, application of stem cell therapy at acute phases of stroke has several advantages. First, treatment temporal windows de- 
termine the mechanisms of stem cell action. Replacement of damaged tissue by exogenously applied cells, or activation of endogenous tissue specific stem cells (neural progenital/stem cells) are the main mechanisms of action of stem cell therapy for chronic stroke. On the contrary, multiple target mechanisms of stem cell action including neuroprotection, immune modulation, and neurorestoration, can be expected when stem cells are applied at the acute phase stroke [48]. Second, the blood-brain barrier opens several days after stroke, at which time stem cells can migrate cross this barrier [49]. Lastly, the levels of chemokines, trophic factors, and relevant microRNAs showed marked increase in the infarcted brain during the acute phase of stroke, but decreased over time [50]. Therefore, more stem cells can migrate into infarcted brain areas when they are administered at the acute phase of stroke.

Allogeneic stem cell transplantation is mandatory when applying stem cell therapy to acute stroke patients because a prolonged culture period is required to obtain a sufficient number of stem cells in autologous stem cell application. Very recently, the results of a phase II, multicenter, doubleblind randomized controlled trial of intravenous application of allogeneic multipotent adult stem cells (MultiStem, Athersys Inc., Cleveland, OH, USA) in acute stroke patients have been reported [5]. MultiStem, an allogeneic "off-the-shelf" cell therapy, during acute phase of stroke (within the 24 to 48 hours window) was found to be safe, and significantly improved recovery and reduced mortality of acute stroke patients at 1 year after injury. Interestingly, the difference in outcome between the MultiStem group and placebo control groups was more pronounced when patients receiving cells at an earlier time point ( $<36$ hours after stroke onset) were included in the analysis [51].

\section{Better cell products}

Cell products can be divided into several generations/cell types based on preparation strategy, such as bone marrow mononuclear cells procured with minimal manipulation, culture expanded MSCs, lineage-directed or preconditioned MSCs, genetically modified stem cells, and neural progenitor/stem cells differentiated from embryonic stem cells/immortalized pluripotent stem cells. The former three stem cell types have already been used in stroke patients, whereas the latter two types of stem cells have only been used for experimental stroke due to safety concerns.

However, there is no one perfect stem cell for treatment of stroke. Better stem cell strategies may differ depending on the expected mechanism of action (neurorestoration vs. neu- roprotection vs. anti-inflammation), and risk-benefit ratio (for example, the safety issue is less important, if the patients has extensive brain injury and is unlikely to recover significantly). The types of stem cells and the mode of application could be tailored depending on the specific characteristics of the patient. For example, stereotaxic injection of immortalized human neural stem cells could be considered in chronic stroke patients [46] while intravenous application of off-the shelf stem cells may be a better strategy to obtain more systemic effects during the acute phase of stroke [5].

For a future stem cell therapy to be widely useful for stroke patients, the following conditions should be met. It should be safe and effective for a broad spectrum of stroke patients (in term of stroke subtype, severity, and vascular territory), it should have the potential to be applied at a broad timeframe after stroke, and by a broad spectrum of physicians (limited need for monitoring or ancillary test) while being relatively inexpensive and cost-effective [52]. However, no such stem cell therapy is currently available.

\section{RECENT ADVANCES AND GUIDELINES}

Recently, there have been significant advances in overcoming the limitations of current stem cell therapies including advances in biotechnology and the cell-free paradigm [53,54]. For example, a cell-free system using extracellular vesicles is attractive compared to cell therapy. Stem cell-derived extracellular vesicles (e.g., exosomes or microvesicle) have low toxicity (e.g., tumor formation, vascular obstruction, and immunity), high stability in circulation, advantages in terms of scalable production and storage, and high efficiency of transport to donor cells. However, these advanced regenerative medical technologies remain at an academic level, and have not reached the clinical stage.

Despite the repetitive failure of endovascular therapy or PFO closure RCTs, device companies could succeed in bringing their devices into the healthcare marketplace after continuous efforts to improve these devices. Caplan et al. [55] stated that "Corporations making medical devices have been allowed to fast-track their products, often without the need for a clinical trial through the device-specific $510(\mathrm{k})$ route. Most new medical devices enter the market via this route, which requires only demonstration of substantial equivalence to a previously marketed device." While products such as endovascular therapy or PFO closure devices have solved clinical problems of substantial scope and proportions, this type of regulation or reimbursement is not currently allowed 
in stem cell therapies. New Japanese guidelines on cell therapy for stroke were developed to encourage the translation of basic scientific research into clinical practice [56]. In these guidelines, regenerative medical technologies are divided into three classes depending on their potential risk to human health (the safety act). After their safety has been confirmed, and results predict the likely efficacy of a regenerative medical product, the company is given conditional or term-limited marketing authorization to enable the timely provision of products to patients (the pharmaceuticals and medical devices act). Caplan et al. [55] stated that "Such Japanese new legislation became effective, and this type of outcomes-based compensation is attractive in that it aligns economic and health interests, but will be difficult to implement in practice."

\section{CONCLUSION}

We could learn many lessons from the successful clinical trials of intervention in stroke patients. As a stroke and stem cell researcher, I suggest several points for the success of stem cell therapy in stroke patients.

First, like investigators of endovascular therapy and PFO closure, stem cell investigators need to analyze the results of existing clinical trials in detail to determine the possible reasons of failures. This requires analyzing many well-designed RCT failures like those of endovascular therapy and PFO closure. We need well-studied failures, rather than ambiguous successes, in stem cell trials for stroke patients. Failure may enable the researcher to reduce uncertainty and search for new opportunities. For example, individual patient data-based meta-analysis of 12 acute myocardial infarction RCTs ( $n=$ 1,252 ) showed that intracoronary cell therapy (autologous stem/progenitor cells) did not show benefit in terms of clinical events or changes in left ventricular function [57]. The investigators were able to present several limitations of past clinical studies and provide future research directions through detailed data analysis [58].

Second, preclinical and clinical researchers need to work together from bench-side (development of novel stem cell therapy) to bed-side (design the clinical trial) in order to increase the applicability of stem cell therapy to patients.

Lastly, professional societies and regulatory authorities need to specify guidelines for stem cell therapy to encourage the translation of basic scientific research into clinical practice. Since the field of stem cell therapy is developing rapidly, establishment of regulations may not follow this rate. It is necessary to continually address this issue with consistent dialogue between stem cell researchers and regulatory authorities.

\section{CONFLICTS OF INTEREST}

No potential conflict of interest relevant to this article was reported.

\section{ACKNOWLEDGMENTS}

This study was supported by grants from the National Research Foundation of Korea (NRF) funded by Ministry of Science, ICT \& Future Planning (NRF-2017R1C1B2002624 and NRF-2014R1A1A1004645).

\section{ORCID}

Oh Young Bang https://orcid.org/0000-0002-7962-8751

\section{REFERENCES}

1. Bang OY. Clinical trials of adult stem cell therapy in patients with ischemic stroke. J Clin Neurol 2016;12:14-20.

2. Lees JS, Sena ES, Egan KJ, Antonic A, Koblar SA, Howells DW, et al. Stem cell-based therapy for experimental stroke: a systematic review and meta-analysis. Int J Stroke 2012; 7:582-8.

3. Prasad K, Sharma A, Garg A, Mohanty S, Bhatnagar S, Johri $S$, et al. Intravenous autologous bone marrow mononuclear stem cell therapy for ischemic stroke: a multicentric, randomized trial. Stroke 2014;45:3618-24.

4. Lee JS, Hong JM, Moon GJ, Lee PH, Ahn YH, Bang OY, et al. A long-term follow-up study of intravenous autologous mesenchymal stem cell transplantation in patients with ischemic stroke. Stem Cells 2010;28:1099-106.

5. Hess DC, Wechsler LR, Clark WM, Savitz SI, Ford GA, Chiu $D$, et al. Safety and efficacy of multipotent adult progenitor cells in acute ischaemic stroke (MASTERS): a randomised, double-blind, placebo-controlled, phase 2 trial. Lancet Neurol 2017;16:360-8.

6. Kim YS, Chung DI, Choi H, Baek W, Kim HY, Heo SH, et al. Fantasies about stem cell therapy in chronic ischemic stroke patients. Stem Cells Dev 2013;22:31-6.

7. Marks PW, Witten CM, Califf RM. Clarifying stem-cell therapy's benefits and risks. N Engl J Med 2017;376:1007-9.

8. Bowman M, Racke M, Kissel J, Imitola J. Responsibilities of health care professionals in counseling and educating patients with incurable neurological diseases regarding "stem 
cell tourism": caveat emptor. JAMA Neurol 2015;72:1342-5.

9. Cote DJ, Bredenoord AL, Smith TR, Ammirati M, Brennum J, Mendez I, et al. Ethical clinical translation of stem cell interventions for neurologic disease. Neurology 2017;88:322-8.

10. Prockop DJ, Prockop SE, Bertoncello I. Are clinical trials with mesenchymal stem/progenitor cells too far ahead of the science? Lessons from experimental hematology. Stem Cells 2014;32:3055-61.

11. Broderick JP, Palesch YY, Demchuk AM, Yeatts SD, Khatri P, Hill MD, et al. Endovascular therapy after intravenous t-PA versus t-PA alone for stroke. N Engl J Med 2013;368:893903.

12. Kidwell CS, Jahan R, Gornbein J, Alger JR, Nenov V, Ajani Z, et al. A trial of imaging selection and endovascular treatment for ischemic stroke. N Engl J Med 2013;368:914-23.

13. Ciccone A, Valvassori L, Nichelatti M, Sgoifo A, Ponzio M, Sterzi R, et al. Endovascular treatment for acute ischemic stroke. N Engl J Med 2013;368:904-13.

14. Wintermark M, Albers GW, Broderick JP, Demchuk AM, Fiebach JB, Fiehler J, et al. Acute stroke imaging research roadmap II. Stroke 2013;44:2628-39.

15. Berkhemer OA, Fransen PS, Beumer D, van den Berg LA, Lingsma HF, Yoo AJ, et al. A randomized trial of intraarterial treatment for acute ischemic stroke. N Engl J Med 2015;372:11-20.

16. Goyal M, Demchuk AM, Menon BK, Eesa M, Rempel JL, Thornton J, et al. Randomized assessment of rapid endovascular treatment of ischemic stroke. N Engl J Med 2015;372:1019-30.

17. Campbell BC, Mitchell PJ, Kleinig TJ, Dewey HM, Churilov $\mathrm{L}$, Yassi N, et al. Endovascular therapy for ischemic stroke with perfusion-imaging selection. N Engl J Med 2015;372: 1009-18.

18. Saver JL, Goyal M, Bonafe A, Diener HC, Levy El, Pereira VM, et al. Stent-retriever thrombectomy after intravenous t-PA vs. t-PA alone in stroke. N Engl J Med 2015;372:2285-95.

19. Bang OY, Lee MJ, Ryoo S, Kim SJ, Kim JW. Patent foramen ovale and stroke-current status. J Stroke 2015;17:229-37.

20. Ryoo S, Chung JW, Lee MJ, Kim SJ, Lee JS, Kim GM, et al. An approach to working up cases of embolic stroke of undetermined source. J Am Heart Assoc 2016;5:e002975.

21. Meier B, Kalesan B, Mattle HP, Khattab AA, Hildick-Smith $D$, Dudek D, et al. Percutaneous closure of patent foramen ovale in cryptogenic embolism. N Engl J Med 2013; 368:1083-91.

22. Carroll JD, Saver JL, Thaler DE, Smalling RW, Berry S, MacDonald LA, et al. Closure of patent foramen ovale versus medical therapy after cryptogenic stroke. N Engl J Med 2013;368:1092-100.

23. Furlan AJ, Reisman M, Massaro J, Mauri L, Adams H, Albers $\mathrm{GW}$, et al. Closure or medical therapy for cryptogenic stroke with patent foramen ovale. N Engl J Med 2012;366:991-9.

24. Kernan WN, Ovbiagele B, Black HR, Bravata DM, Chimowitz MI, Ezekowitz MD, et al. Guidelines for the prevention of stroke in patients with stroke and transient ischemic attack: a guideline for healthcare professionals from the American Heart Association/American Stroke Association. Stroke 2014;45:2160-236.

25. Messe SR, Gronseth G, Kent DM, Kizer JR, Homma S, Rosterman L, et al. Practice advisory: recurrent stroke with patent foramen ovale (update of practice parameter): report of the guideline development, dissemination, and implementation subcommittee of the American Academy of Neurology. Neurology 2016;87:815-21.

26. Thaler DE, Wahl A. Critique of closure or medical therapy for cryptogenic stroke with patent foramen ovale: the hole truth? Stroke 2012;43:3147-9.

27. Saver JL, Carroll JD, Thaler DE, Smalling RW, MacDonald LA, Marks DS, et al. Long-term outcomes of patent foramen ovale closure or medical therapy after stroke. N Engl J Med 2017;377:1022-32.

28. Mas JL, Derumeaux G, Guillon B, Massardier E, Hosseini H, Mechtouff $L$, et al. Patent foramen ovale closure or anticoagulation vs. antiplatelets after stroke. N Engl J Med 2017;377:1011-21.

29. Sondergaard L, Kasner SE, Rhodes JF, Andersen G, Iversen HK, Nielsen-Kudsk JE, et al. Patent foramen ovale closure or antiplatelet therapy for cryptogenic stroke. N Engl J Med 2017;377:1033-42.

30. Lee PH, Song JK, Kim JS, Heo R, Lee S, Kim DH, et al. Cryptogenic stroke and high-risk patent foramen ovale: the DEFENSE-PFO trial. J Am Coll Cardiol 2018;71:2335-42.

31. Abe K, Yamashita T, Takizawa S, Kuroda S, Kinouchi H, Kawahara N. Stem cell therapy for cerebral ischemia: from basic science to clinical applications. J Cereb Blood Flow Metab 2012;32:1317-31.

32. Gonzalez-Garza MT, Cruz-Vega DE. Regenerative capacity of autologous stem cell transplantation in elderly: a report of biomedical outcomes. Regen Med 2017;12:169-78.

33. Kim H, Han JW, Lee JY, Choi YJ, Sohn YD, Song M, et al. Diabetic mesenchymal stem cells are ineffective for improving limb ischemia due to their impaired angiogenic capability. Cell Transplant 2015;24:1571-84.

34. Chen J, Ye X, Yan T, Zhang C, Yang XP, Cui X, et al. Adverse 


\section{PRECISION AND FUTURE MIEDICINE}

Stem cell therapy in human stroke

effects of bone marrow stromal cell treatment of stroke in diabetic rats. Stroke 2011;42:3551-8.

35. Yan T, Venkat P, Chopp M, Zacharek A, Ning R, Cui Y, et al. Neurorestorative therapy of stroke in type 2 diabetes mellitus rats treated with human umbilical cord blood cells. Stroke 2015;46:2599-606.

36. Boltze J, Nitzsche F, Jolkkonen J, Weise G, Posel C, Nitzsche B, et al. Concise review: increasing the validity of cerebrovascular disease models and experimental methods for translational stem cell research. Stem Cells 2017;35:1141-53.

37. Wang D, Wang S, Huang S, Zhang Z, Yuan X, Feng X, et al. Serum IFN- $\gamma$ predicts the therapeutic effect of mesenchymal stem cells transplantation in systemic lupus erythematosus patients. Stem Cells Transl Med 2017;6:1777-85.

38. Mallinson DJ, Dunbar DR, Ridha S, Sutton ER, De la Rosa O, Dalemans W, et al. Identification of potential plasma microrna stratification biomarkers for response to allogeneic adipose-derived mesenchymal stem cells in rheumatoid arthritis. Stem Cells Transl Med 2017;6:1202-6.

39. Stinear CM, Byblow WD, Ackerley SJ, Barber PA, Smith MC. Predicting recovery potential for individual stroke patients increases rehabilitation efficiency. Stroke 2017;48:1011-9.

40. Bath PM, Lees KR, Schellinger PD, Altman H, Bland M, Hogg $C$, et al. Statistical analysis of the primary outcome in acute stroke trials. Stroke 2012;43:1171-8.

41. Saver JL, Altman H. Relationship between neurologic deficit severity and final functional outcome shifts and strengthens during first hours after onset. Stroke 2012; 43:1537-41.

42. Stinear CM, Barber PA, Smale PR, Coxon JP, Fleming MK, Byblow WD. Functional potential in chronic stroke patients depends on corticospinal tract integrity. Brain 2007; 130:170-80.

43. Cramer SC, Parrish TB, Levy RM, Stebbins GT, Ruland SD, Lowry DW, et al. Predicting functional gains in a stroke trial. Stroke 2007;38:2108-14.

44. Chen DC, Lin SZ, Fan JR, Lin CH, Lee W, Lin CC, et al. Intracerebral implantation of autologous peripheral blood stem cells in stroke patients: a randomized phase II study. Cell Transplant 2014;23:1599-612.

45. Kim SJ, Moon GJ, Chang WH, Kim YH, Bang OY; STARTING-2 (STem cell Application Researches and Trials In NeuroloGy-2) collaborators. Intravenous transplantation of mesenchymal stem cells preconditioned with early phase stroke serum: current evidence and study protocol for a randomized trial. Trials 2013;14:317.
46. Kalladka D, Sinden J, Pollock K, Haig C, McLean J, Smith $W$, et al. Human neural stem cells in patients with chronic ischaemic stroke (PISCES): a phase 1, first-in-man study. Lancet 2016;388:787-96.

47. Sun JM, Song AW, Case LE, Mikati MA, Gustafson KE, Simmons R, et al. Effect of autologous cord blood infusion on motor function and brain connectivity in young children with cerebral palsy: a randomized, placebo-controlled trial. Stem Cells Transl Med 2017;6:2071-8.

48. Savitz SI. Cell therapies: careful translation from animals to patients. Stroke 2013;44(6 Suppl 1):S107-9.

49. Yang Y, Rosenberg GA. Blood-brain barrier breakdown in acute and chronic cerebrovascular disease. Stroke 2011; 42:3323-8.

50. Hill WD, Hess DC, Martin-Studdard A, Carothers JJ, Zheng $J$, Hale D, et al. SDF-1 (CXCL12) is upregulated in the ischemic penumbra following stroke: association with bone marrow cell homing to injury. J Neuropathol Exp Neurol 2004;63:84-96.

51. Mays RW, Savitz SI. Intravenous cellular therapies for acute ischemic stroke. Stroke 2018;49:1058-65.

52. Adams HP Jr, Nudo RJ. Management of patients with stroke: is it time to expand treatment options? Ann Neurol 2013;74:4-10.

53. Bang OY, Kim EH, Cha JM, Moon GJ. Adult stem cell therapy for stroke: challenges and progress. J Stroke 2016;18: 256-66.

54. Kusuma GD, Carthew J, Lim R, Frith JE. Effect of the microenvironment on mesenchymal stem cell paracrine signaling: opportunities to engineer the therapeutic effect. Stem Cells Dev 2017;26:617-31.

55. Caplan Al, Mason C, Reeve B. The 3Rs of cell therapy. Stem Cells Transl Med 2017;6:17-21.

56. Houkin K, Shichinohe H, Abe K, Arato T, Dezawa M, Honmou $O$, et al. Accelerating cell therapy for stroke in japan: regulatory framework and guidelines on development of cell-based products. Stroke 2018;49:e145-52.

57. Gyongyosi M, Wojakowski W, Lemarchand P, Lunde K, Tendera M, Bartunek J, et al. Meta-Analysis of Cell-based CaRdiac stUdiEs (ACCRUE) in patients with acute myocardial infarction based on individual patient data. Circ Res 2015;116:1346-60.

58. Gyongyosi M, Wojakowski W, Navarese EP, Moye LA; ACCRUE Investigators. Meta-analyses of human cell-based cardiac regeneration therapies: controversies in meta-analyses results on cardiac cell-based regenerative studies. Circ Res 2016;118:1254-63. 